\title{
Analysis of coding sequences for tissue inhibitor of metalloproteinases 1 (TIMP1) and 2(TIMP2) in patients with aneurysms
}

\author{
Xiaoju Wang ${ }^{\mathrm{a}}$, Gerard Tromp ${ }^{\mathrm{a}}$, C. William Cole ${ }^{\mathrm{b}}$, Alain Verloes ${ }^{\mathrm{c}}$, \\ Natzi Sakalihasan $^{\mathrm{d}}$, Sungpil Yoon ${ }^{\mathrm{a}}$, Helena Kuivaniemi ${ }^{\mathrm{a}, *}$ \\ ${ }^{a}$ Center for Molecular Medicine and Genetics, and Department of Surgery, Wayne State University, School of Medicine, 3106 Gordon \\ H. Scott Hall of Basic Medical Sciences, 540 East Canfield Avenue, Detroit, MI 48201, USA \\ ${ }^{\mathrm{b}}$ Dalhousie University, Halifax, Nova Scotia, Canada \\ ${ }^{\mathrm{c}}$ Wallonia Center for Human Genetics, Liège University, Liège, Belgium \\ ${ }^{\mathrm{d}}$ Department of Cardiovascular Surgery, Sart Tilman University Hospital, Liège, Belgium
}

Received 16 September 1998; accepted 22 October 1998

\begin{abstract}
Aneurysms are characterized by dilation, i.e. expansion and thinning of all the arterial wall layers, which is accompanied by remodeling of the connective tissue. Genes involved in the regulation of tissue remodeling are therefore candidate genes. We analyzed TIMP1 and TIMP2 coding sequences in 12 individuals with abdominal aortic aneurysms (AAA), one individual with AAA and intracranial aneurysms (IA), four individuals with IA and two clinically unaffected individuals. We identified two nucleotide variants in both the TIMP1 and the TIMP2 coding sequences. All differences occurred in the third base positions of codons and were neutral polymorphisms. A significant difference was observed in the frequency of TIMP2 nt 573 polymorphism between 168 alleles from AAA patients and 102 control alleles. (c) 1999 Elsevier Science B.V./International Society of Matrix Biology. All rights reserved.
\end{abstract}

Keywords: Aortic aneurysms; Connective tissue; Direct sequencing; Intracranial aneurysms; Polymorphism

\section{Introduction}

Rupture of an abdominal aortic (AAA) or intracranial (IA) aneurysm is a significant cause of mortality and morbidity, and $1-6 \%$ of the population in the USA and other industrialized countries harbor aneurysms (see Verloes et al., 1996). Despite the

\footnotetext{
* Corresponding author.

Abbreviations: AAA, abdominal aortic aneurysm; cDNA, complementary DNA; IA, intracranial aneurysm; PCR, polymerase chain reaction; TIMP1, tissue inhibitor of metalloproteinase 1; TIMP2, tissue inhibitor of metalloproteinase 2; nt, nucleotide
}

major advances in surgical treatment, the survival rate after a ruptured aneurysm is low. Early diagnosis of aneurysms is, therefore, important. If it were possible to predict who is at risk for developing an aneurysm, diagnostic efforts (ultrasonography, computerized tomography and magnetic resonance imaging) could be directed towards those at risk.

Familial predisposition to both AAAs and IAs is now well recognized (see Verloes et al., 1996; Ronkainen et al., 1997). The possible genetic factors involved in the development of aneurysms include (see Verloes et al., 1996): (a) structural components of arteries; (b) enzymes degrading the structural molecules; and (c) inhibitors of the proteolytic process. 
DNA sequencing of 50 aortic aneurysm patients (Tromp et al., 1993) and 55 IA or carotid artery dissection patients (Kuivaniemi et al., 1993) revealed that mutations in type III procollagen are an infrequent cause of aneurysms.

The development of aneurysms is associated with remodeling of the extracellular matrix, including breakdown of structural components of the vascular wall (see Verloes et al., 1996). Collagenase activity and production of 92-kDa gelatinase (MMP9) are increased in ruptured aneurysmal aorta (see Verloes et al., 1996). The increased proteolytic activity could be due to overexpression of the enzymes or down-regulation of their inhibitors. In fact, decreased levels of tissue inhibitors of metalloproteinases (TIMPs) in AAAs have been reported (see Verloes et al., 1996). Furthermore, the ratio of matrix metalloproteinase (MMP) mRNA amount to TIMP mRNA was higher in AAA than in normal aortas (Tamarina et al., 1997). The relative TIMP deficiency could be due to local tissue conditions inhibiting the expression or mutations in the primary structure of the TIMP genes. There are at least four members in the TIMP family, all of which were cloned, sequenced and mapped onto human chromosomes (see Olson et al., 1998).

We studied the coding sequences of TIMP1 and TIMP2 in patients with AAA and/or IA to determine whether mutations in the TIMP genes are associated with aneurysms.

\section{Materials and methods}

This study was initiated at Thomas Jefferson University and was approved by the Institutional Review Committees of Thomas Jefferson University and Wayne State University School of Medicine. Skin biopsies obtained after written informed consent were used to establish fibroblast cultures. RNA was isolated, cDNA synthesized, PCR products purified and genomic DNA isolated as described previously (Tromp et al., 1993). Oligonucleotide primers based on the cDNA sequences of TIMP1 (TIMP1-I, CGCGAATTCAGATCCAGCGCCCAGAGAG; TIMP1II, CGCGGATCCGGAAGAAAGATGGGAGTGGG; Docherty et al., 1985) and TIMP2 (TIMP2-II, TTTATTCATGCTGTTTCCAGGAAGGG; TIMP2VI, CGGCCCCGCCCGCCCAGC; Stetler-Stevenson et al., 1990) were used in PCR to amplify all the coding sequences. Because of the high GC content in the $5^{\prime}$ end of the TIMP2, many PCR conditions failed, but Q-solution and Qiagen PCR kit were used successfully (Qiagen Inc., Santa Clarita, CA, USA).

The PCR products were sequenced directly using either Sequenase ${ }^{\circledR}$ (US Biochemical Corporation, Cleveland, OH, USA) and $\left[\alpha-{ }^{33} \mathrm{P}\right] \mathrm{dATP}$ (NEN/DuPont), or Thermo Sequenase ${ }^{\circledR}$ (Amersham
Life Science, Inc., Cleveland, OH, USA). The samples were electrophoresed on a Sequagel- ${ }^{\circledR}$ (National Diagnostics, Atlanta, GA, USA) or on glycerol-tolerant gels (Amersham Life Science, Inc., Cleveland, $\mathrm{OH}$, USA).

The sequence variants were confirmed by PCRbased restriction endonuclease assays. The gender of all samples was confirmed by Y-chromosome specific PCR (Research Genetics, Huntsville, AL, USA). For genomic PCRs, primers were designed based on published sequences (Genbank accession number D11139; Hammani et al., 1996). Primer sequences and PCR conditions are available from the corresponding author upon request.

\section{Results and discussion}

To investigate the possibility that aneurysms are caused by defects in the genes for TIMP1 or TIMP2, the sequences of the coding regions of TIMP1 and TIMP2 were determined in 19 unrelated individuals (12 had AAA, one had AAA and IA, four had IA, and two were clinically unaffected). All except one of the 17 aneurysm patients had a family history for the disease. The type III procollagen cDNA sequences in all of these individuals were normal (Kuivaniemi et al., 1993; Tromp et al., 1993).

The sequence analyses carried out here provided $671 \mathrm{nt}$ of TIMP1 cDNA sequences (all $621 \mathrm{nt}$ of coding sequences) from each individual. Two sequence variations were found. AAA patient JIMM429 had C/T nt 323 (proline codon at amino acid position 87 changes from CCC to CCT). All the other 18 individuals had $\mathrm{C}$ at $\mathrm{nt} 323$. Another sequence change was found at nt 434 , also reported by others (Tilson et al., 1993). Six individuals had $\mathrm{C}$ at this site, 11 had $\mathrm{T}$ and two individuals were heterozygous $\mathrm{C} / \mathrm{T}$. The sequence change converted the phenylalanine codon TTC at amino acid position 124 to TTT.

For TIMP2, we analyzed 750-nt (all 660 nt of coding sequences), and two sequence variations were identified. AAA patient JIMM398 had C/T at nt 306. Another difference, $\mathrm{G}$ to A transition, occurred at nt 573 in three patients (JIMM332, JIMM430 and JIMM257), all of whom were heterozygous for this change. Both variations occurred at the third positions of codons and did not change the amino acids.

The frequencies of these variations were determined among 102 control alleles and 168 alleles from AAA patients (11 of the patients used for DNA sequencing and 73 additional unrelated AAA patients). The TIMP1 gene includes four exons (Genbank accession number: D11139), and the variants are in the second and third exons. Since TIMP1 is on the $\mathrm{X}$ chromosome, we report the allele frequencies separately in males and females (Table 1). 
Table 1

Frequencies of the polymorphisms in TIMP1 and TIMP2 genes

\begin{tabular}{|c|c|c|c|c|c|c|c|c|}
\hline \multirow[t]{3}{*}{ Location } & \multirow[t]{3}{*}{ Chr. ${ }^{a}$} & \multicolumn{3}{|l|}{ Controls $^{\mathrm{b}}$} & \multicolumn{4}{|c|}{ Unrelated AAA patients $^{\mathrm{c}}$} \\
\hline & & \multicolumn{3}{|c|}{ Allele frequency ${ }^{\mathrm{d}}$} & \multicolumn{3}{|c|}{ Allele frequency ${ }^{\mathrm{d}}$} & \multirow[t]{2}{*}{$P$-value ${ }^{\mathrm{f}}$} \\
\hline & & $\bar{M}$ & $\mathrm{~F}$ & Het. $^{\mathrm{e}}$ & $\overline{\mathrm{M}}$ & $\mathrm{F}$ & Het. $^{\mathrm{e}}$ & \\
\hline \multirow[t]{2}{*}{ TIMP1 nt 323} & \multirow[t]{2}{*}{$\mathrm{X}$} & C: $0.966(28)$ & $1.000(44)$ & \multirow[t]{2}{*}{0} & $0.953(61)$ & $0.950(38)$ & \multirow[t]{2}{*}{0.023} & M: 1.0000 \\
\hline & & $\mathrm{T}: 0.034$ (1) & $0.000(0)$ & & $0.047(3)$ & $0.050(2)$ & & F: 0.2238 \\
\hline \multirow[t]{2}{*}{ TIMP1 nt 434} & \multirow[t]{2}{*}{$\mathrm{X}$} & C: $0.483(14)$ & $0.273(12)$ & \multirow[t]{2}{*}{0.157} & $0.578(37)$ & $0.625(25)$ & \multirow[t]{2}{*}{0.107} & M: 0.5005 \\
\hline & & T: 0.517 (15) & $0.727(32)$ & & $0.422(27)$ & $0.375(15)$ & & F: 0.0019 \\
\hline \multirow[t]{2}{*}{ TIMP2 nt 306} & \multirow[t]{2}{*}{17} & C: $0.931(54)$ & $0.977(43)$ & \multirow[t]{2}{*}{0.157} & $0.961(123)$ & $0.975(39)$ & \multirow[t]{2}{*}{0.071} & M: 0.6089 \\
\hline & & $\mathrm{T}: 0.069(4)$ & $0.023(1)$ & & $0.039(5)$ & $0.025(1)$ & & F: 1.0000 \\
\hline \multirow[t]{2}{*}{ TIMP3 nt 573} & \multirow[t]{2}{*}{17} & G: $0.793(46)$ & $0.886(39)$ & \multirow[t]{2}{*}{0.212} & $0.914(117)$ & $0.950(38)$ & \multirow[t]{2}{*}{0.155} & M: 0.0374 \\
\hline & & A: $0.207(12)$ & $0.114(5)$ & & $0.086(11)$ & $0.050(2)$ & & $F: 0.4370$ \\
\hline
\end{tabular}

${ }^{\mathrm{a}}$ Chromosomal localization of the gene.

${ }^{\mathrm{b}}$ Twenty-nine controls were males and 22 were females (all 51 were from the US).

${ }^{\mathrm{c}}$ Sixty-four AAA patients were males (21 US, 17 Belgian, 13 Canadian, 7 Swedish, 3 British and 3 Finnish) and 20 were females (11 US, 6 Canadian, 2 Finnish and one Italian).

${ }^{\mathrm{d}}$ Numbers in parentheses indicate number of alleles observed. M, males; F, females.

${ }^{\mathrm{e}}$ Observed heterozygosity. For TIMP1, calculated using female alleles only.

${ }^{\mathrm{f}}$ Comparison of allele frequencies between control and AAA groups using Fischer's exact test.

No significant differences in the frequencies of the nt 323 polymorphism were found between controls and AAA patients. The frequencies between the two female groups were, however, significantly different $(P$ $=0.0019)$ for the nt 434 polymorphism.

The TIMP2 gene contains five exons (Hammani et al., 1996), and the sequence variants are in exons 1 and 3 . The TIMP2 sequence variants were polymorphisms with minor allele frequencies of 0.049 and 0.167 for the nt 306 and nt 573, respectively (Table 1), with no significant differences between the controls and the AAA group with nt 306 polymorphism. The frequencies of nt 573 polymorphism were different between the control and AAA groups in males. In further analyses with 30 additional US control individuals, and by dividing the groups according to ethnic origin, the frequencies remained significantly different in males (Table 2). Among the US males, the difference between controls and AAA patients was even more significant (Table 2).

In summary, no mutations were found in the TIMP1 and TIMP2 genes in aneurysm patients. The differences in allele frequencies of nt 573 TIMP2 polymorphism between the control and AAA groups are interesting preliminary findings that need further follow-up with larger groups and carefully selected control groups for each ethnic group. It is possible that a mutation in the TIMP1 or TIMP2 gene contributes to

Table 2

Comparison of the allele frequencies for TIMP2 nt 573 polymorphism

\begin{tabular}{|c|c|c|c|c|c|}
\hline \multirow[t]{2}{*}{ Ethinicity } & \multicolumn{2}{|l|}{ Controls $^{\mathrm{a}}$} & \multicolumn{3}{|c|}{ Unrelated AAA patients $^{\mathrm{b}}$} \\
\hline & $\mathrm{M}^{\mathrm{c}}$ & $\mathrm{F}^{\mathrm{c}}$ & $\mathrm{M}^{\mathrm{c}}$ & $\mathrm{F}^{\mathrm{c}}$ & $P$-value ${ }^{\mathrm{d}}$ \\
\hline US & $\begin{array}{l}\text { G: } 0.804(74) \\
\text { A: } 0.196(18)\end{array}$ & $\begin{array}{l}0.861(62) \\
0.139(10)\end{array}$ & $\begin{array}{l}0.976(41) \\
0.024(1)\end{array}$ & $\begin{array}{l}1.000(22) \\
0.000(0)\end{array}$ & $\begin{array}{l}\text { M: } 0.0174 \\
\text { F: } 0.1098 \\
M+F: 0.0033\end{array}$ \\
\hline Others & $\begin{array}{l}\text { G: } \\
\text { A: }\end{array}$ & & $\begin{array}{l}0.884(76) \\
0.116(10)\end{array}$ & $\begin{array}{l}0.889(16) \\
0.111(2)\end{array}$ & $\begin{array}{l}\text { M: } 0.2122^{\mathrm{e}} \\
\text { F: } 1.0000^{\mathrm{e}}\end{array}$ \\
\hline Total & $\begin{array}{l}\text { G: } 0.804(74) \\
\text { A: } 0.196(18)\end{array}$ & $\begin{array}{l}0.861(62) \\
0.139(10)\end{array}$ & $\begin{array}{l}0.914(117) \\
0.086(11)\end{array}$ & $\begin{array}{l}0.950(38) \\
0.050(2)\end{array}$ & $\begin{array}{l}\text { M: } 0.0300 \\
\text { F: } 0.2549 \\
\text { M + F: } 0.0156\end{array}$ \\
\hline
\end{tabular}

\footnotetext{
${ }^{\mathrm{a}}$ Eighty-two US American control individuals, 36 females and 46 males.

${ }^{\mathrm{b}}$ For details, see Table 1 .

${ }^{\mathrm{c}}$ Numbers in parentheses indicate number of alleles observed. M, males, F, females.

${ }^{\mathrm{d}}$ Comparison of allele frequencies between control and AAA groups using Fisher's exact test.

${ }^{\mathrm{e}}$ Comparison across populations may not be valid due to allele frequency differences; however, it is evident that adding the non-US patients to the total does not inflate the $P$-values; rather, it is conservative.
} 
the disease process in patients with aneurysms. Such mutations could be either mutations in the promoter sequence or large-scale rearrangements in the genome, not easily detected by direct sequencing of RT-PCR products.

The polymorphisms will also be useful for genetic analyses in other diseases. For example TIMP2 is a candidate gene for autosomal-dominant retinitis pigmentosa (Bardien et al., 1995), and altered activities have been reported in tumor tissues (Bramhall et al., 1997).

\section{Acknowledgements}

This work was supported by grants from the National Institutes of Health (HL 45996) and the American Heart Association, Michigan Affiliate, and by funds from the Wayne State University School of Medicine.

\section{References}

Bardien, S., Ebenezer, N., Greenberg, J., et al., 1995. An eighth locus for autosomal dominant retinitis pigmentosa is linked to chromosome 17q. Hum. Mol. Genet. 4, 1459-1462.

Bramhall, S.R., Neoptolemos, J.P., Stamp, G.W., Lemoine, N.R. 1997. Imbalance of expression of matrix metalloproteinases (MMPs) and tissue inhibitors of the matrix metalloproteinases (TIMPs) in human pancreatic carcinoma. J. Pathol. 182, 347-355.

Docherty, A.J.P., Lyons, A., Smith, B.J., Wright, E.M., Stephens, P.E., Harris, T.J.R., 1985. Sequence of human tissue inhibitor of metalloproteinases and its identity to erythroid-potentiating activity. Nature (London) 7, 66-69.

Hammani, K., Blakis, A., Morsette, D., et al., 1996. Structure and characterization of the human tissue inhibitor of metalloproteinases-2 gene. J. Biol. Chem. 271, 25498-25505.

Kuivaniemi, H., Prokop, D.J., Wu, Y., et al., 1993. Exclusion of mutations in the gene for type III collagen (COL3A1) as a common cause of intracranial aneurysms or cervical artery dissections by sequence analysis of the coding sequences of type III collagen from 55 unrelated patients. Neurology 43, 2652-2658.

Olson, T.M., Hirohata, S., Ye, J., Leco, K., Seldin, M.F., Apte, S.S., 1998. Cloning of the tissue inhibitor of metalloproteinase- 4 gene (TIMP4) and localization of the TIMP4 and Timp4 genes to human chromosomes 3p25 and mouse chromosome 6, respectively. Genomics 51, 148-151.

Ronkainen, A., Hernesniemi, J., Puranen, M., et al., 1997. Familial intracranial aneurysms. Lancet 349, 380-384.

Stetler-Stevenson, W.G., Brown, P.D., Onisto, M., Levy, A.T., Liotta, L.A., 1990. Tissue inhibitor of metalloproteinases-2 (TIMP2) mRNA expression in tumor cell lines and human tumor tissues. J. Biol. Chem. 265, 13933-13938.

Tamarina, N.A., McMillan, W.D., Shively, V.P., Pearce, W.H., 1997. Expression of matrix metalloproteinases and their inhibitors in aneurysms and normal aorta. Surgery 122, 264-271.

Tilson, M.D., Reilly, J.M., Brophy, C.M., Webster, E.L., Barnett, T.R., 1993. Expression and sequence of the gene for tissue inhibitor of metalloproteinases in patients with abdominal aortic aneurysms. J. Vasc. Surg. 18, 266-270.

Tromp, G., Wu, Y., Prockop, D.J., et al., 1993. Sequencing of cDNA from 50 unrelated patients reveals that mutations in the triplehelical domain of type III procollagen are an infrequent cause of aortic aneurysms. J. Clin. Invest. 91, 2539-2545.

Verloes, A., Sakalihasan, N., Limet, R., Koulischer, L., 1996. Genetic aspects of abdominal aortic aneurysms. Ann. N.Y. Acad. Sci. $800,44-55$. 